\title{
Phone Triage
}

\author{
Deb Gauldin, RN, PMS
}

\begin{abstract}
In this column, a childbirth educator humorously discusses the perils of automated voice-recognition phone systems.
\end{abstract}

Journal of Perinatal Education, 18(1), 56-57, doi: 10.1624/105812409X396499

Keywords: humor, childbirth education

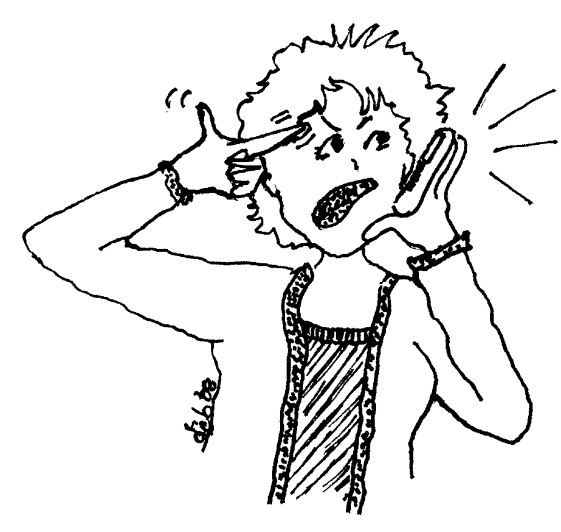

"Of course, you will want to follow any specific instructions given by your health practitioner." This is the first part of the perinatal educator's mantra. The second part has to do with assuring clients that it is okay to call their practitioner or health-care facility with any concerns. That could prove to be more difficult than it sounds.

"I can't get through the maze of prompts when I call the office," exclaimed a very frustrated and very pregnant friend of mine. I could hear the obvious anger in her voice, but I suspect the automated voice-recognition "robot" could not. "If you are calling for a prescription refill, press 4 . If you are cramping fewer than 15 minutes but greater than 7 minutes apart, press 11 . If you lost or cannot locate your mucus plug, press 9."

I am sure phone triage systems are cost effective, yet I'd wager they also contribute to stress-related illnesses and emergency-room admissions.

Recently, I flew to a speaking engagement, but my guitar did not. Each time I called to check on the instrument, I followed a Habitrail of prompts. Eventually, an automated voice would tell me to try again, and so I would. I tried again and again. My blood pressure crept higher. Pressing the pound key or zero would not take me to a "real" person, even when I pushed the buttons very, very hardwhile cursing.

I tried a second customer service number, dutifully "saying or speaking" flight numbers and arrival cities, multidigit baggage claim ticket numbers, and hotel contact information. Just as "Voice-Recognition Lady" was about to ask for my SAT scores and current weight in kilograms, a glitch occurred. 
"Please say or speak your last name," the monotone voice requested. "Gauldin," I responded. "I think you said Solvent," she replied. I calmly indicated this was incorrect and we began the loop again. "Gaul-Din," I carefully enunciated and waited. "I think you said Taco Bell," came her indifferent reply.

I completely lost it. "I did not say Taco Bell," I shrieked to no one. "Why in the world would I say Taco Bell?" I continued to rant. "You have my ticket confirmation numbers and VISA. How hard is it to verify my phonetically uncomplicated last name? I did not marry a man named Taco Bell!"

Finally, a real person responded. "Thank you for calling," she said. "May I have your arrival city and 36-digit claim tag number?",

A multigravida could give birth while navigating a menu like this one. As for me, a trip to the clinic for an antianxiety script ought to do it.

DEB GAULDIN is a childbirth educator who travels nationally presenting keynotes and workshops. Her CDs and tapes contain humor and songs about pregnancy, childbirth, and the adjustment to parenthood. For booking information or to purchase Deb's recordings, call 800-682-2347 or visit her Web site (www.debgauldin.com).

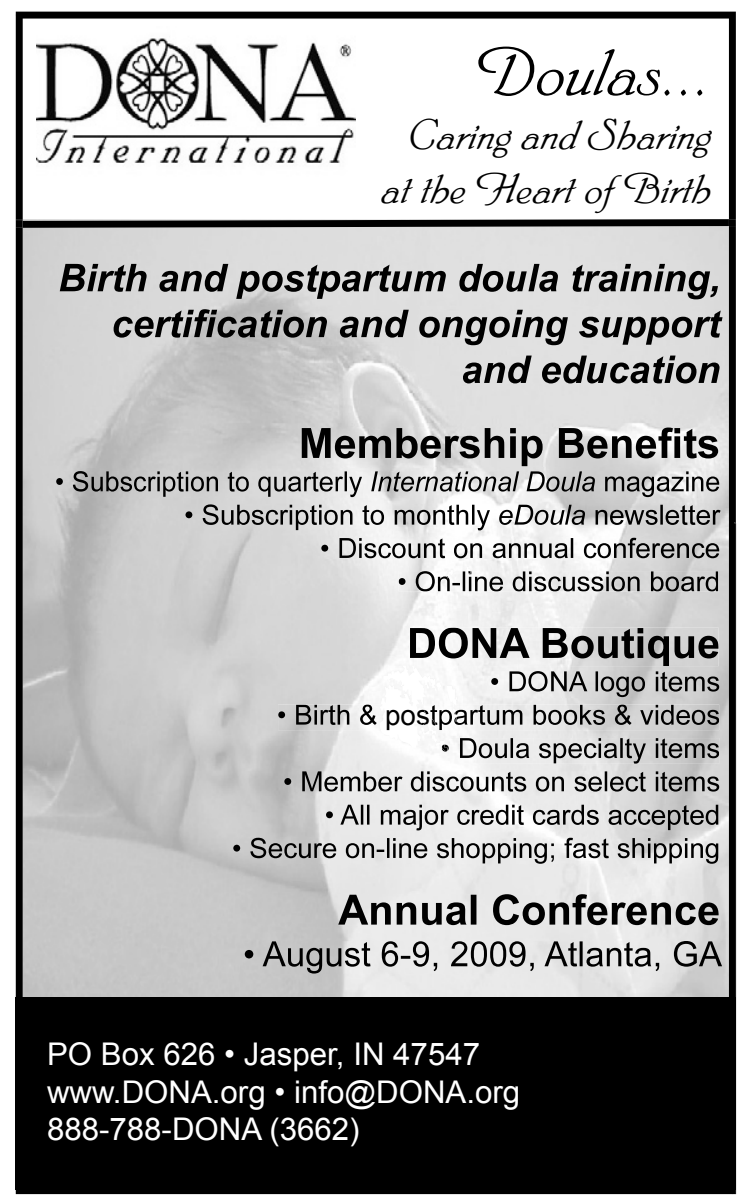

